\title{
Genetic and physiological studies of the CiaH-CiaR two-component signal-transducing system involved in cefotaxime resistance and competence of Streptococcus pneumoniae
}

\author{
Philippe Giammarinaro, Michel Sicard and Anne-Marie Gasc
}

Laboratoire de

Microbiologie et de

Génétique Moléculaire du

CNRS, Université Paul

Sabatier, 118 route de

Narbonne, 31062 Toulouse

Cedex, France
Author for correspondence: Anne-Marie Gasc. Tel: +335613359 71. Fax: + 33561335886. e-mail : gasc@ibcg.biotoul.fr

\begin{abstract}
A mutation in the ciaH gene of Streptococcus pneumoniae induces cefotaxime resistance and transformation deficiency. ciaH encodes a putative sensor protein that belongs to the family of signal-transducing histidine kinases. This gene is adjacent to ciaR, which encodes a DNA-binding protein involved in the regulation of genes responding to environmental signals sensed by the histidine kinase. The authors have characterized a mutation that induces reversion of both cefotaxime resistance and transformation deficiency. It is a T/A deletion in the ciaR gene resulting in the synthesis of a truncated protein containing only 125 amino acids instead of 224 . The ciaH mutation requires a functional CiaR protein for expression. Northern blot analysis, using ciaR-ciaH as a probe, revealed one MRNA from the wild-type strain, indicating that the two genes constitute an operon. Comparisons of Northern blots show that the operon is constitutively activated in the strain carrying only the ciaH mutation. In the wild-type strain the activation occurs when the $\mathrm{Ca}^{2+}$ concentration is very low, demonstrating that $\mathrm{Ca}^{2+}$ is the environmental signal. The pleiotropic effects caused by the ciaH mutation include sensitivity to antibiotics and toxins, the ability to form protoplasts and the susceptibility to lysis with deoxycholate. Null-mutants were constructed in both genes and the particular features of the ciaR null mutant determined. It is able to grow in cholinedeprived medium, and competence development occurs in a phosphatedeprived competence medium (CH-maleate), suggesting that the CiaH-CiaR system regulates several pathways, including teiochoic acid synthesis.
\end{abstract}

Keywords: Streptococcus pneumoniae, PBP, phosphate, calcium, competence

\section{INTRODUCTION}

The increase of $\beta$-lactam-resistant pneumococcal clinical isolates is becoming a serious problem in antibiotic therapy. The resistance of these strains is not due to $\beta$ lactamase, but to penicillin-binding proteins (PBPs). These minor components of the bacterial membrane are often affected in their ability to bind this antibiotic, accounting for the resistance of these strains (Williamson et al., 1980; Hakenbeck et al., 1980). However, so far quantitative correlations between resistance levels and modification of specific PBPs have not been possible because clinical isolates are not

Abbreviation: PBP, penicillin-binding protein. isogenic and the wild-type strains from which they originated are not known. Moreover, sequence comparison has shown that $\beta$-lactam resistance results from horizontal transfer of several long stretches of DNA from other species (Dowson et al., 1993). Thus the situation appears to be especially complex in clinical resistant strains. In order to bypass such complications, a series of independent, spontaneous mutants resistant to a high level of cefotaxime, a cephalosporin that binds to the PBPs, except PBP2B (Hakenbeck et al., 1987), were isolated from Streptococcus pneumoniae R6, a rough laboratory strain (Laible \& Hakenbeck, 1987). Genetic analysis by DNA-mediated transformation of a strain which is 64 -fold more resistant than the original wild-type strain (C506) has shown that mutations of two genes, affecting respectively PBP2X and PBP3, 
accounted for two levels of resistance (Seroude et al., 1993; Selakovich-Chenu et al., 1997). A third level of resistance was obtained without any modification of a PBP. It was found that this high level of resistance resulted from a mutation in the $c i a H$ gene, which encodes a histidine kinase sensor closely linked to a response regulator, $\mathrm{CiaR}$; both gene products are members of the family of signal-transducing twocomponent systems (Guenzi et al., 1994). An unexpected observation was that this highly resistant strain was no longer competent. Competence refers to a physiological state of a culture and its ability to be transformed by DNA. In the pneumococcus all bacteria become competent at the same time at the end of the exponential phase, and shortly thereafter competence disappears (Thomas, 1955). Competence requires several ions, especially $\mathrm{Ca}^{2+}$ (Fox \& Hotchkiss, 1957; Trombe et al., 1992), $\mathrm{Mg}^{2+}$ (Seto \& Tomasz, 1976) and $\mathrm{Zn}^{2+}$ (Dintilhac \& Claverys, 1997).

The aim of this work was to investigate the relationship between resistance to cefotaxime and loss of competence by isolating mutants affected in these genes and studying their properties under several conditions. We will show that the $\mathrm{CiaH}-\mathrm{CiaR}$ system functions as an operon and that $\mathrm{Ca}^{2+}$ is involved in its regulation.

\section{METHODS}

Bacterial strains and plasmids. These are listed in Table 1.

Growth conditions and media. The general growth conditions of $S$. pneumoniae and the composition of $\mathrm{CH}$ medium were as described by Tiraby \& Fox (1974). CH-maleate medium had the same composition as $\mathrm{CH}$ medium with the following exceptions: (1) $\mathrm{K}_{2} \mathrm{HPO}_{4}(0 \cdot 05 \mathrm{M})$ was replaced by maleate buffer $(0.05 \mathrm{M}, \mathrm{pH} 7),(2)$ the $\mathrm{pH}$ of the medium was adjusted to $7 \cdot 8$ by addition of $\mathrm{NaOH}$. The composition of MS mediun was as described by Sicard (1964). MS" medium had the same composition as MS medium except for the $\mathrm{CaCl}_{2}$ concentration $(0.5 \mathrm{mM}$ instead of $5 \mathrm{mM}$ in MS). Phosphate concentration modifications of MS* were obtained by addition of potassium phosphate buffer $(\mathrm{pH} 7 \cdot 6)$.

Transformation. Transformation of S. pneumoniae followed published procedures (Tiraby \& Fox, 1974). Cefotaximeresistant transformants were screened on blood agar plates containing the desired concentration of cefotaxime. Streptomycin resistance was screened with $200 \mu \mathrm{g}$ streptomycin $\mathrm{ml}^{-1}$. Escherichia coli was transformed by electroporation with a 'Gene-Pulser' following procedures supplied by BioRad.

DNA techniques. The PCR fragments were obtained and purified as described previously (Gasc et al., 1998). Sequencing was done using the Circumvent Thermal Cycle Sequencing Kit (Biolabs). The position (according to numbering of the EMBL sequence $\mathrm{X} 77249$ ) and sequence of oligonucleotide primers used for amplification and sequencing of $c i a R$ and $c i a H$ genes are as follows: (i) upstream primers, $5^{\prime}$ - ggggatcc $_{219}$ ATAAAAATCTTATTGGTTGAGG-3', 5' ${ }_{533}$ GAACTTAAAATGCGGAaTTCAGGCC-3'， 5'-ggaattcc ${ }_{1428}$ GATTGTGGTCGTGATGGC-3' ; (ii) downstream primers, $5^{\prime}{ }_{{ }_{95.5}}$ CAGGGTGAAGACACCGAAGcTTGCG-3', 5' ${ }_{1665}$ CAAACTCGATGCAA GCTTTCGC-3', $5^{\prime}$ - cccaagctt $_{2212}$ ATTTTTTCTTTTT-
AGATGGTGTCT-3'. The small letters indicate modified bases or primer extension. The underlined letters indicate EcoRI or Bam HI restriction sites for forward primers and HindIII restriction sites for downstream primers.

Plasmid constructions and insertional inactivations of the ciaR and ciaH genes. To create the knockout mutants, the method of insertional duplication mutagenesis, a homologydirected insertion of foreign DNA, was used (Mejean et al., 1981). Internal gene fragments of $c i a R$ and $c i a H$ were amplified using total DNA from R800 and the following pairs of oligonucleotide primers containing terminal restriction sites:

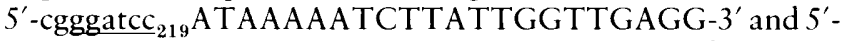

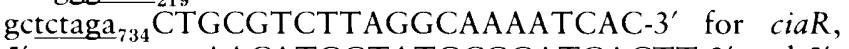
$5^{\prime}$-gctctagag - $_{900}$ AACATGGTATGCGGATGACTT-3' and $5^{\prime}$ cgggatcc $_{1451}$ AAACTAGCCATCACGACCACAA-3' for ciaH. PCR products were subsequently cloned into $B a m \mathrm{HI} / \mathrm{XbaI}$ restricted $\mathrm{pR} 350$. The resulting plasmids (pHG2 and $\mathrm{pHG} 3$ respectively) were used to transform $S$. pneumoniae. Transformants were selected using $200 \mu \mathrm{g}$ spectinomycin $\mathrm{ml}^{-1}$ (Dintilhac et al., 1997).

MIC determination and assay of PBPs. These were done as previously published (Selakovitch-Chenu et al., 1993).

Protoplast formation. Protoplasts were produced in a buffer composed of $0 \cdot 1 \mathrm{M}$ Tris $/ \mathrm{HCl}, 1 \mathrm{mM} \mathrm{MgCl}$ and $3 \mathrm{mM} \beta$ mercaptoethanol at $\mathrm{pH} 7.6$ as described by Lacks \& Neuberger (1975). Samples were tested for sensitivity to osmotic shock in water before and after incubation for various periods of time.

RNA isolation and Northern blot analysis. Total RNA extractions and Northern blot analysis were as described by Mortier-Barriere et al. (1998). The RNA size standard was purchased from Biolabs. The ciaR-ciaH probe was obtained by $\left[\alpha{ }^{32} \mathrm{P}\right] \mathrm{ATP}$ incorporation using the Amersham Megaprime labelling system into a PCR fragment obtained with the $5^{\prime}$ - -gggatcc- ${ }_{219}$ ATAAAAATCTTATTGGTTGAGG-3' and $5^{\prime}$ - cccaagctt $_{2212}$ ATTTTTTCTTTTTAGATGGTGTCT-3' primers. Photos were analysed with a phosphoimager and the band intensities were quantified with the TINA program (Moleculars Dynamics).

\section{RESULTS}

\section{Isolation of a mutation in the ciaR gene}

Previous experiments had shown that it was possible to obtain highly resistant bacteria by transformation of the cefotaxime-sensitive recipient strain R801 with DNA from the resistant strain C506. Forty clones were isolated at cefotaxime concentrations varying from 0.05 to $0.08 \mu \mathrm{g} \mathrm{ml}^{-1}$. The transformants $(801 \mathrm{~A})$ were all resistant to $0 \cdot 15 \mu \mathrm{g} \mathrm{ml}^{-1}$ of this drug (Seroude et al., 1993). The penicillin affinity of PBP2X was reduced in these transformants (Fig. 1). We transformed five resistant strains 801A with DNA from strain C506 and selected transformants which occurred at a frequency corresponding to the transfer of one gene. They were resistant to $0.3 \mu \mathrm{g} \mathrm{ml}^{-1}$ (strains 801B). The PBP electrophoretic profile shows increased labelling of PBP3 in these transformants. Indeed PBP3 was present in C506 whereas recipient sensitive strain R801 was deficient in this protein (Fig. 1) (Selakovitch-Chenu et al., 1997). An 801B strain was transformed by C506 DNA. Transformants were obtained on plates containing 0.5 and 
Table 1. Strains and plasmids used in this study

\begin{tabular}{|c|c|c|}
\hline $\begin{array}{l}\text { Bacterium or } \\
\text { plasmid }\end{array}$ & Genotype/characteristics & Source or reference \\
\hline \multicolumn{3}{|l|}{ Strains } \\
\hline \multicolumn{3}{|l|}{ S. pneumoniae } \\
\hline $\mathrm{C} 506$ & $\mathrm{R} 6, p b p X$ penA ciaH* & Laible \& Hakenbeck (1987) \\
\hline R801 & $\mathrm{R} 6 \mathrm{x}$ derivative, dac $A$ & Lefevre et al (1979) \\
\hline $801 \mathrm{~A}$ & $\mathrm{R} 801, p b p \mathrm{X}$ & Seroude et al. (1993) \\
\hline $801 \mathrm{~B}$ & $801 \mathrm{~A}, \operatorname{dac} A^{+}$ & $\begin{array}{l}\text { Selakovitch-Chenu et al. } \\
\text { (1997) }\end{array}$ \\
\hline $80 \mathrm{IC}$ & 801B, ciaH* & This study \\
\hline $801 \mathrm{Crev}$ & $801 C, c i a R$ & This study \\
\hline $\mathrm{R} 800$ & R6 derivative & Lefevre et al. (1979) \\
\hline $800 \mathrm{ciaH}^{*}$ & $\mathrm{R} 800$, cia $H^{*}$ & This study \\
\hline 800 ciaR $^{\text {null }}$ & R800, ciaR::pHG2 & This study \\
\hline $800 \mathrm{ciaH}^{\text {null }}$ & R800, ciaH::pHG3 & This study \\
\hline \multicolumn{3}{|l|}{ E. coli } \\
\hline $\mathrm{DH} 5 \alpha$ & $\begin{array}{l}\text { supE44 } \Delta \text { lac UI69( } \phi 80 \text { lacZ } \Delta \mathrm{M} 15) \text { hsdR17 } \\
\text { recA1 endA1 gyrA96 thi-1 relA1 }\end{array}$ & GIBCO-BRL \\
\hline \multicolumn{3}{|l|}{ Plasmids* } \\
\hline pR350 & $\mathrm{pSK}^{+}$derivative, $A \mathrm{p}^{\mathrm{r}} \mathrm{Sp}^{\mathrm{r}}$ & Dintilhac et al. (1997) \\
\hline pHG2 & $\begin{array}{l}\text { pR350 derivative carrying a PCR-generated } \\
515 \text { bp ciaR fragment }\end{array}$ & This study \\
\hline pHG3 & $\begin{array}{l}\text { pR350 derivative carrying a PCR-generated } \\
550 \text { bp ciaH fragment }\end{array}$ & This study \\
\hline pEG2 & $\begin{array}{l}\text { pJDC } 9 \text { derivative carrying the } c i a H^{*} \\
\text { mutation }\end{array}$ & Guenzi et al. (1994) \\
\hline
\end{tabular}

* Plasmids replicate in E. coli only.

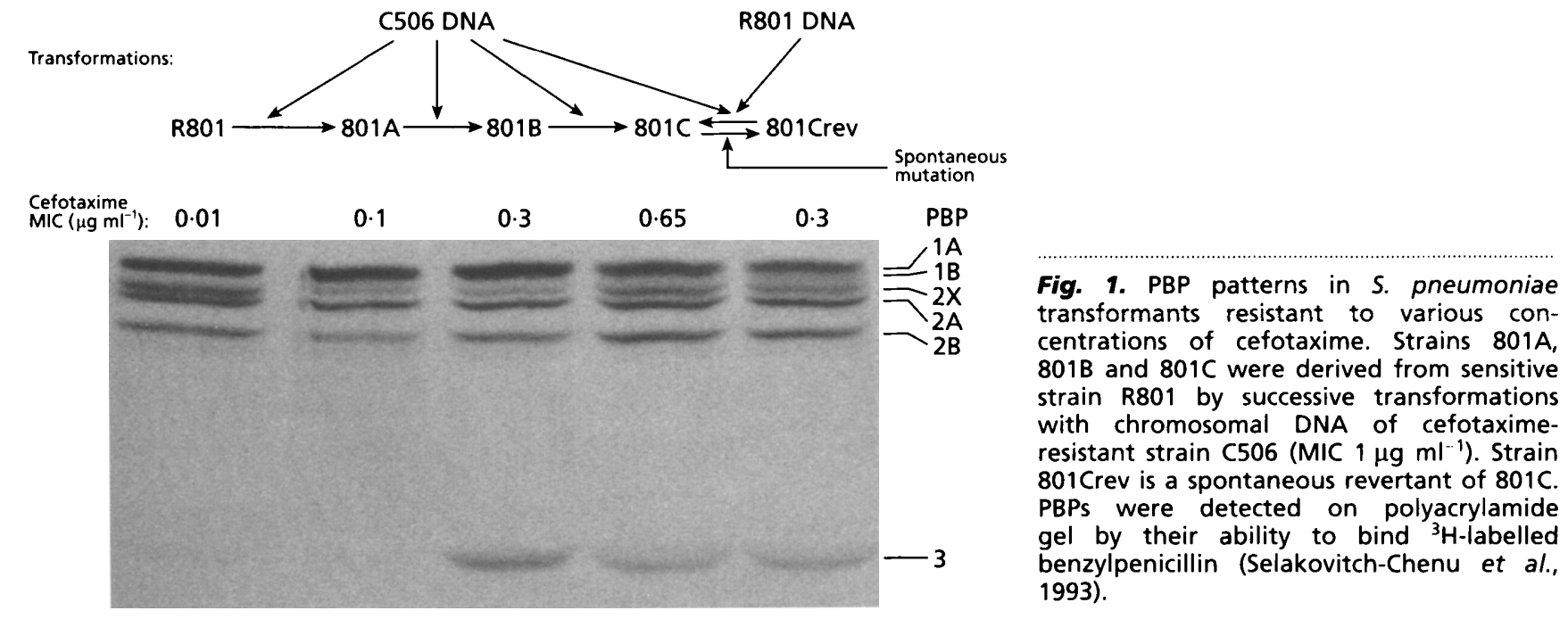

$0.7 \mu \mathrm{g}$ cefotaxime $\mathrm{ml}^{-1}$, at a frequency corresponding to the transfer of one gene. Eleven clones were isolated. They were resistant to $0.65 \mu \mathrm{g}$ cefotaxime $\mathrm{ml}^{-1}$, defining a third level of resistance (strains 801C). The PBP profiles were not affected in these clones. As the level of resistance of these strains was slightly lower than that of the original mutant C506 $\left(1 \mu \mathrm{g} \mathrm{m}^{-1}\right)$, we suspected that another mutation was present in C506 and not in 801C. We therefore tried to transform 801C with C506 DNA and subsequently plated on a concentration of cefotaxime that kills strain $801 \mathrm{C}$. We failed to isolate strains more resistant to cefotaxime than $801 \mathrm{C}$. As a control, 


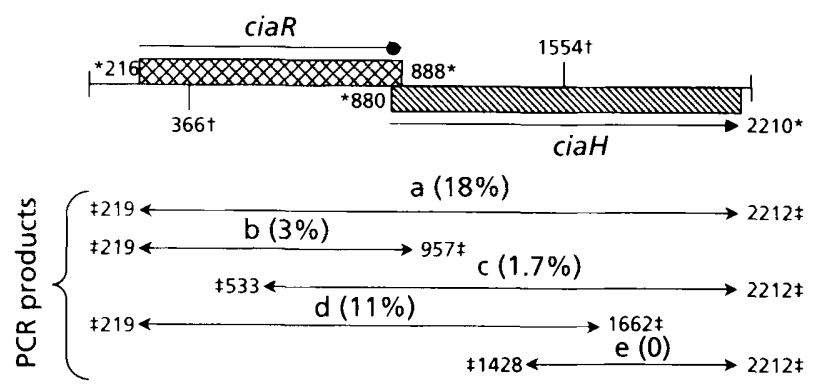

Fig. 2. Localization of the $801 \mathrm{Crev}$ mutation in the ciaR-ciaH operon. Top, ciaR-ciaH operon. *Initiation and stop codon positions of ciaR and $c i a H$ genes; tphosphorylation sites of CiaR and $\mathrm{CiaH}$ proteins. Bottom, PCR products used to transform strain $801 \mathrm{Crev}$. Transformants were selected for their resistance to cefotaxime $\left(0.6 \mu \mathrm{g} \mathrm{ml}{ }^{1}\right)$; their frequencies are indicated in parentheses. $\neq$ Extremities of PCR products.

we transformed $801 \mathrm{C}$ with DNA from a cefotaximesensitive strain, containing the marker str 41 that confers resistance to $0.2 \mathrm{mg}$ streptomycin $\mathrm{ml}^{-1}$. Very few transformants resistant to streptomycin were obtained. However, these transformants had reverted to a lower level of cefotaxime resistance $\left(0.3 \mu \mathrm{g} \mathrm{ml} \mathrm{ml}^{-1}\right)$. These revertants were fully competent, whereas bacteria resistant to $0.65 \mu \mathrm{g} \mathrm{m} \mathrm{m}^{-1}$ were non-transformable. The original strain C.506 was also non-transformable, as already reported (Laible \& Hakenbeck, 1991). These results show that there is a mutation in a gene of strain C.506 that, in addition to the other two, increases resistance to $0.65 \mu \mathrm{g}$ cefotaxime $\mathrm{ml}^{-1}$ and blocks competence in $801 \mathrm{C}$. Guenzi et al. (1994) have shown that this mutation is localized in the ciaH gene, resulting from a $\mathrm{Thr}_{230}$ to Pro substitution (it will be referred to later as ciaH" in this paper). The defect of transformation may occur at the DNA-uptake level, since plasmids could not transform the highly resistant bacteria, whereas electrotransformants were obtained at a normal frequency (Seroude et al., 1993). Moreover, these non-transformable strains were unable to be induced to competence by the competence factor (Seroude et al., 1993) and did not produce this competence factor themselves (Guenzi et al., 1994). One such revertant $(801 \mathrm{Crev})$ was cultured for further study.

When the spontaneous revertant $801 \mathrm{Crev}$ was transformed by wild-type DNA or C506 DNA, transformants resistant to a concentration of $0.65 \mu \mathrm{g}$ cefotaxime $\mathrm{ml}^{-1}$ were isolated at a frequency corresponding to the transfer of one gene. Strain $801 \mathrm{Crev}$ therefore contains a mutation, absent in wild-type or in C506, that reduces cefotaxime resistance and restores competence. The PBP profile of this revertant was identical to that of strain $801 \mathrm{C}$ (Fig. 1). A candidate region for harbouring this mutation is the ciaR-ciaH locus that affects cefotaxime resistance without PBP modification.

To localize the mutation that yields the revertant phenotype, several parts of the ciaR-ciaH locus were amplified by PCR using wild-type DNA. The revertant strain (801Crev) was transformed with these fragments, and colonies were selected at $0.6 \mu \mathrm{g}$ cefotaxime $\mathrm{ml}^{-1}$. Transformants were obtained when the fragment tested contained the region between nucleotides 533 and 957 (Fig. 2), encoding the C-terminal part of CiaR and the first 25 amino acids of $\mathrm{CiaH}$. We have sequenced this region from the $801 \mathrm{Crev}$ strain and found one $\mathrm{T}$ deleted in the sequence TTTA (578 to 581), resulting in a stop codon 15 nucleotides downstream. The mutated CiaR protein, therefore, must be truncated in its C-terminal region. Since this region is required for fixation on DNA (Stock et al., 1990), it is likely that the mutated protein has lost its regulatory properties. However, it cannot be excluded that this frameshift mutation in ciaR may block the expression of ciaH by a polar effect, since inactivation of $c i a H$ by itself does not inhibit competence (Guenzi et al., 1994).

\section{Construction of isogenic strains carrying a mutation in the $c i a H$ and $c i a R$ genes}

The discovery of mutations in the two-component signal-transducing system affecting cefotaxime resistance and natural competence resulted from isolation of highly resistant mutants from strains already mutated in several PBP genes. To investigate the effect of isolated mutations on the ciaH and ciaR genes, we tried to transfer these mutations to a wild-type strain. We chose as the recipient strain $\mathrm{R} 800$, an $\mathrm{R} 6$ clone isogenic to R801, because R800's spontaneous mutation rate is much lower than that of R801 (Tiraby \& Sicard, 1973; Tiraby \& Fox, 1973), due to efficient repair of mismatched bases in $\mathrm{R} 800$, and deficient repair in $\mathrm{R} 801$ $\left(\mathrm{Hex}^{-}\right)$. This precaution was undertaken to protect against unwanted mutations.

A competent culture of strain $\mathrm{R} 800$ was transformed with plasmid pEG2 DNA. This plasmid carries the ciaH $^{*}$ mutation that confers cefotaxime resistance (Guenzi et al., 1994). Selection was carried out at a concentration of $0.04 \mu \mathrm{g}$ cefotaxime $\mathrm{ml}^{-1}$. Transformants were recovered at a frequency of $3 \%$ as expected for the transfer of one gene; spontaneous mutants were very rare. One of these transformants was subcultured and the presence of the original mutation was ascertained by sequencing a PCR product of the ciaH region. This strain was named $800 \mathrm{ciaH}^{*}$. It is noteworthy that the increased resistance to cefotaxime resulting from the cia $H^{*}$ mutation is expressed in a wildtype strain (which is resistant to $0.02 \mu \mathrm{g}$ cefotaxime $\mathrm{ml}^{-1}$ ) as well as a strain carrying mutations in PBP genes.

To inactivate $c i a H$, we inserted an internal fragment of this gene into the plasmid pR350 (Dintilhac et al., 1997). This plasmid is unable to replicate in the pneumococcus and carries a marker of resistance to $200 \mu \mathrm{g}$ spectinomycin $\mathrm{ml}^{-1}$. To confer resistance to this antibiotic, the plasmid has to be integrated into the chromosome by homologous recombination in the ciaH sequence. We transformed strain R800 with the DNA of this plasmid. 


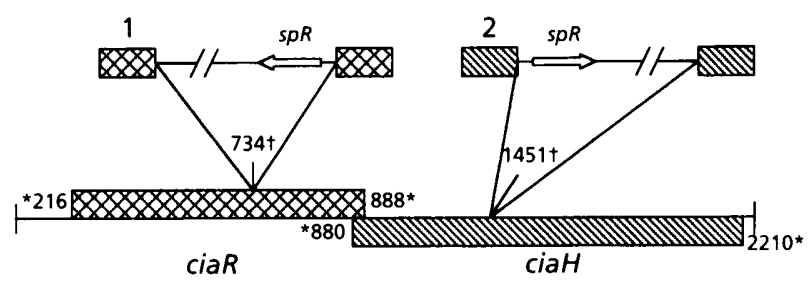

Fig. 3. Structure of $800 \mathrm{ciaR}^{\text {null }}$ (1) and $800 \mathrm{ciaH}^{\text {null }}$ (2) mutants. Mutants were obtained by insertional-duplication mutagenesis as described in Methods. * Initiation and stop codon positions of $\mathrm{ciaR}$ and $\mathrm{CiaH}$; tpositions where pHG2 (1) or pHG3 (2) plasmids were inserted. $s p R$, spectinomycin-resistance gene.

Spectinomycin-resistant transformants were selected. One of them was further tested for the insertion of the plasmid genome into the $c i a H$ gene. We subsequently isolated a strain carrying an insertion in the ciaR gene by the same procedure (Fig. 3). The isolation of such strains carrying an interrupted ciaH $\left(800 \mathrm{ciaH}^{\text {null }}\right)$ or ciaR (800ciaR ${ }^{\text {null }}$ ) gene shows that these are not essential genes, confirming earlier reports (Guenzi et al., 1994).

\section{Effect of ciaH and ciaR mutations on competence}

We have seen previously that the $\mathrm{ciaH}^{*}$ mutation abolishes competence. Using the different mutants that we constructed, we investigated the effect of ciaR and ciaH on competence. It was suggested by Guenzi et al. (1994) that a homology exists between proteins CiaR and $\mathrm{CiaH}$ and proteins PhoB and PhoR. The PhoB/ PhoR system is activated by phosphate deprivation in $E$. coli (Makino et al., 1985). A possible role of phosphate on competence was also suggested by Tomasz \& Hotchkiss (1964), who reported that when the phosphate buffer used in competence medium is replaced by a maleate buffer, competence is abolished. We tested the competence of the strains mutated in the ciaR-ciaH locus in complete competence medium $(\mathrm{CH})$ and in this medium deprived of phosphate ( $\mathrm{CH}$-maleate). Wildtype strains (R801 and R800) as well as strains mutated in PBP genes (801B) are competent in $\mathrm{CH}$ medium but not in $\mathrm{CH}$-maleate medium, a control confirming the observation of Tomasz \& Hotchkiss (1964) (Table 2). However, inactivation of the ciaR gene (strains $800 \mathrm{ciaR}^{\text {null }}$ and $801 \mathrm{Crev}$ ) restores competence in the absence of phosphate.

This result suggests that the $\mathrm{CiaR} / \mathrm{CiaH}$ system is involved in the phosphate effect on competence. As the inactivation of either ciaR or ciaH does not affect competence in phosphate medium, the regulation of competence should be negatively controlled by this system. The $\mathrm{ciaH}^{*}$ mutation should result in a constitutive production of the $\mathrm{CiaR}$ and $\mathrm{CiaH}$ proteins. It is noteworthy that strain $800 \mathrm{ciaH}^{\text {null }}$ is slightly competent in $\mathrm{CH}$-maleate medium. This suggests that the CiaR protein, despite being non-phosphorylated by the $\mathrm{CiaH}$ protein in this mutant, is able to partially inhibit
Table 2. Competence in $\mathrm{CH}$ and in $\mathrm{CH}$-maleate media

Competence was estimated by determining the frequency of streptomycin-resistant transformants (see Methods). +, Competent (frequency of streptomycin-resistant transformants $\geqslant 1 \%$.; - , non-competent (frequency of streptomycin-resistant transformants $\leqslant 3 \times 10^{-5} \%$ ).

\begin{tabular}{|lcc|}
\hline Strain & \multicolumn{2}{c|}{ Competence on: } \\
\cline { 2 - 3 } & $\mathrm{CH}$ & $\mathrm{CH}$-maleate \\
\hline R801 & + & - \\
$801 \mathrm{~B}$ & + & - \\
$801 \mathrm{C}$ & - & - \\
$801 \mathrm{Crev}$ & + & + \\
R800 & + & - \\
$800 \mathrm{ciaH}^{*}$ & - & - \\
800 ciaR $^{\text {null }}$ & + & - \\
800 ciaH $^{\text {null }}$ & + & - \\
\hline
\end{tabular}

* Frequency of streptomycin-resistant transformants $3 \times 10^{-3} \%$.

competence. To test the role of phosphate in the regulation of the $\mathrm{CiaR} / \mathrm{CiaH}$ system, we studied the transcription of these genes.

\section{Transcription of ciaR and $\mathrm{ciaH}$}

To study the control of several two-component signal sensing systems implicating phosphorylation in their autoregulation, we used a defined growth medium in which phosphate concentration can be modified. We reduced the $\mathrm{Ca}^{2+}$ concentration in the synthetic growth medium of pneumococcus (Sicard, 1964) 10-fold to avoid precipitation of calcium phosphate at high phosphate concentration (medium MS*). Total RNAs were extracted and Northern analysis was performed (see Methods). A single $2 \cdot 2 \mathrm{~kb}$ fragment was observed (Fig. 4). This shows that the two genes are transcribed as a unique RNA, i.e. ciaR-ciaH is an operon. The size of the mRNA is as expected from the DNA sequences of these regions. In the wild-type the transcription increases 10fold when the phosphate concentration is increased from 1 to $50 \mathrm{mM}$. However, transcription of the operon in the $800 \mathrm{ciaH}^{*}$ strain is high whatever the phosphate concentration. The $\mathrm{ciaH}^{*}$ mutation, therefore, results in a constitutively active operon, confirming what was previously proposed (Guenzi et al., 1994). The activation of the operon by an increase in the amount of phosphate in a wild-type culture shows that the $\mathrm{CiaR} / \mathrm{CiaH}$ system is not analogous to the $\mathrm{PhoB} / \mathrm{PhoR}$ system. In other bacteria this latter system is positively autoregulated when phosphate concentration decreases, and we observed the opposite in S. pneumoniae.

The phosphate concentration in the growth medium could act directly or indirectly on the $\mathrm{CiaR} / \mathrm{CiaH}$ system. Calcium or magnesium phosphate precipitated in the medium might reduce the amount of available 

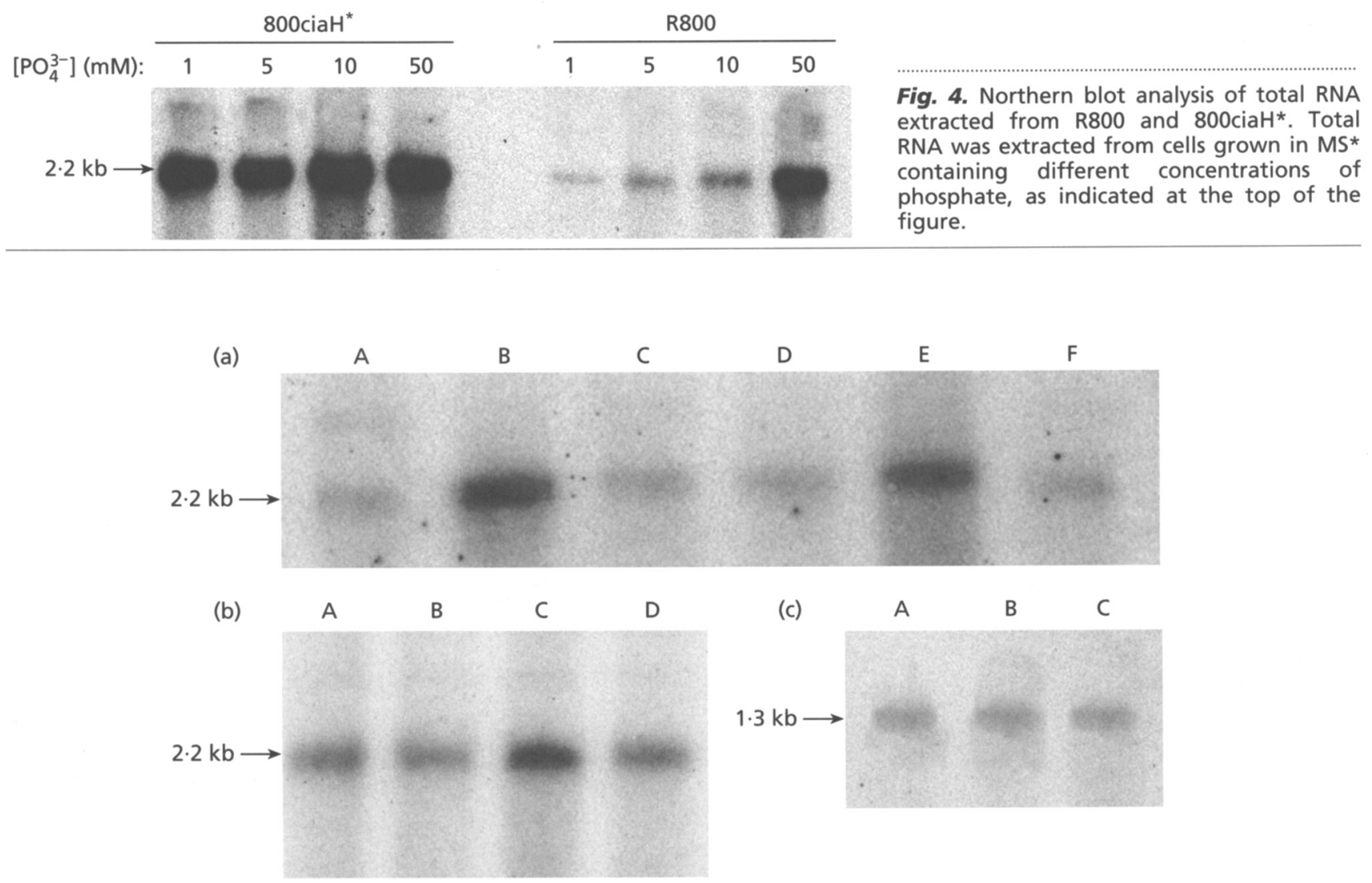

\begin{abstract}
Fig. 5. Northern blot analysis of the transcription of the ciaR-ciaH operon. Northern blot analysis was performed as described in Methods. $(a, b)$ Total RNAs were extracted from strain R800 grown as follows. (a) Cells were grown in MS* containing $1 \mathrm{mM} \mathrm{PO}{ }_{4}^{3}$ to $O_{550} 0.3$ and incubated for $10 \mathrm{~min}$ in different conditions: $A$, control; $B,+0.5$ mM EGTA; $C$, $+5 \mathrm{mM} \mathrm{CaCl} 2 ; D_{1}+5 \mathrm{mM} \mathrm{MgCl}_{2} ; \mathrm{E}_{1}+0.5 \mathrm{mM}$ EGTA and $5 \mathrm{mM} \mathrm{CaCl}_{2} ; \mathrm{F}_{\text {, }}+0.5 \mathrm{mM}$ EDTA. (b) Cells were grown in MS* containing $10 \mathrm{mM}$ phosphate to $\mathrm{OD}_{550} 0.3$ and incubated for $10 \mathrm{~min}$ in different conditions: $\mathrm{A}$, control; $\mathrm{B},+5 \mathrm{mM} \mathrm{CaCl}$; $C_{1}+0.5 \mathrm{mM}$ EGTA; $D_{1}+5 \mathrm{mM} \mathrm{MgCl} 2$. (c) Total RNAs were extracted from strain 800 ciaH ${ }^{\text {null }}$ grown in $\mathrm{MS}^{*}$ containing $1 \mathrm{mM}$ phosphate to $O_{550} 0.3$ and incubated for $10 \mathrm{~min}$ in different conditions: $A$, control; $B$, $+0.5 \mathrm{mM}$ EGTA; C, $+10 \mathrm{mM}$ phosphate.
\end{abstract}

cations to the bacteria. We cultivated the wild-type strain R800 in MS* medium containing $1 \mathrm{mM}$ phosphate to a cell density of $\mathrm{OD}_{550} O \cdot 3$. We subsequently added to the culture several combination of EGTA, EDTA, $\mathrm{Ca}^{2+}$ or $\mathrm{Mg}^{2+}$ for $10 \mathrm{~min}$ before extracting the RNAs and we measured the transcription of the ciaR-ciaH operon as described above. EGTA alone at a concentration of $0.5 \mathrm{mM}$ increased the transcription threefold (Fig. 5a). $\mathrm{Ca}^{2+}$ addition reduced the effect of EGTA twofold. The other combinations did not significantly affect the mRNA production. Since EGTA is a chelator of $\mathrm{Ca}^{2+}$, these results suggest that $\mathrm{Ca}^{2+}$ inhibits transcription of the ciaR-ciaH operon. The lack of effect of EDTA, which is also able to chelate $\mathrm{Ca}^{2+}$ but less efficiently than EGTA, could be explained by the low concentration of this chelator. If EGTA induces the operon by chelating $\mathrm{Ca}^{2+}$, one would expect that addition of $\mathrm{Ca}^{2+}$ alone should inhibit this transcription. However, this is not observed (see Fig. 5a), probably because at the low phosphate concentration used $(1 \mathrm{mM})$, this transcription is already fully repressed by the free $\mathrm{Ca}^{2+}$ in the medium. We also grew the cells in $10 \mathrm{mM}$ phosphate and added, as before, $\mathrm{Ca}^{2+}$, EGTA or $\mathrm{Mg}^{2+}$, and noted (Fig. 5b) that $\mathrm{Ca}^{2+}$ addition reduced the transcription twofold.

We submitted a $800 \mathrm{ciaH}^{\text {nuil }}$ culture to a similar treatment to determine the role played by the $\mathrm{ciaH}$ gene product. Phosphate or EGTA did not affect the transcription as expected from the proposed model (see Fig. $5 \mathrm{c})$. The size of the RNA fragment was $1.3 \mathrm{~kb}$, confirming that the insert plasmid had interrupted the transcription in the ciaH gene.

These results suggest that the ciaR-ciaH operon is repressed by $\mathrm{Ca}^{2+}$. Addition of either phosphate or EGTA would reduce the available $\mathrm{Ca}^{2+}$, indirectly derepressing this system. Such regulation would depend on the integrity of the $\mathrm{CiaH}$ protein acting as a $\mathrm{Ca}^{2+}$ sensor. This protein would phosphorylate CiaR when $\mathrm{Ca}^{2+}$ concentration is reduced. This hypothesis led us to re-evaluate the effect of $\mathrm{Ca}^{2+}$ on competence and cefotaxime resistance. 
Table 3. Effects of chelators and divalent cations on transformation frequency

Transformations were performed with saturating DNA concentrations. Results are expressed as the percentage of streptomycinresistant transformants. In the control, transformants were scored in transformation medium without supplement.

\begin{tabular}{|c|c|c|c|c|c|c|c|c|c|c|}
\hline \multirow[t]{2}{*}{ Strain } & \multirow[t]{2}{*}{ Control } & \multirow{2}{*}{$\begin{array}{c}\text { EGTA } \\
(0.5 \mathrm{mM})\end{array}$} & \multicolumn{3}{|c|}{ EGTA $(0.5 \mathrm{mM})+\left[\mathrm{Ca}^{2+}\right] \mathrm{mM}:$} & \multicolumn{3}{|c|}{ EGTA $(0.5 \mathrm{mM})+\left[\mathrm{Mg}^{2+}\right] \mathrm{mM}:$} & \multirow{2}{*}{$\begin{array}{c}\text { EDTA } \\
(10 \mathrm{mM})\end{array}$} & \multirow{2}{*}{$\begin{array}{l}\text { EDTA }(10 \mathrm{mM}) \\
+\mathrm{Ca}^{2+}(20 \mathrm{mM})\end{array}$} \\
\hline & & & 0.05 & 0.5 & 5 & 0.05 & 0.5 & 5 & & \\
\hline $\mathrm{R} 800$ & $1 \cdot 3$ & $0 \cdot 08$ & $0 \cdot 05$ & $0 \cdot 4$ & $0 \cdot 64$ & 0.05 & $0 \cdot 06$ & $0 \cdot 05$ & 0 & 0.05 \\
\hline 800 ciaR $^{\text {null }}$ & $1 \cdot 6$ & $0 \cdot 35$ & $0 \cdot 5$ & $2 \cdot 0$ & $1 \cdot 2$ & $0 \cdot 23$ & $0 \cdot 22$ & $0 \cdot 21$ & 0 & $0 \cdot 2$ \\
\hline 800 ciaH $^{\text {null }}$ & $1 \cdot 5$ & $0 \cdot 3$ & $0 \cdot 15$ & 1.6 & $1 \cdot 1$ & $0 \cdot 25$ & $0 \cdot 17$ & $0 \cdot 25$ & 0 & $0 \cdot 23$ \\
\hline
\end{tabular}

\section{Effect of $\mathrm{Ca}^{2+}$ on competence}

A major role of $\mathrm{Ca}^{2+}$ in $S$. pneumoniae transformation is at the entry step of DNA (Fox \& Hotchkiss, 1957; Seto $\&$ Tomasz, 1976). Competent cultures of several strains were treated for $10 \mathrm{~min}$ with chelating agents at concentrations that reduced transformation frequencies; they were then transformed with DNA carrying a streptomycin-resistance marker. In these conditions the transformation frequency of the wild-type strain was reduced 16-fold in the presence of $0.5 \mathrm{mM}$ EGTA, whereas the transformation frequency of $800 \mathrm{ciaH}^{\text {null }}$ or $800 \mathrm{ciaR}^{\text {null }}$ was only reduced by a factor of 4 . The simultaneous addition of $0.5 \mathrm{mM} \mathrm{CaCl}$ abolished the inhibitory effect of this chelating agent on these two mutants whereas $5 \mathrm{mM} \mathrm{CaCl}$, was not enough to produce the same reversal of the wild-type strain. $\mathrm{Mg}^{2+}$ addition was ineffective. We also treated competent cultures with $10 \mathrm{mM}$ EDTA; at this concentration transformation was abolished. The addition of $20 \mathrm{mM}$ $\mathrm{CaCl}_{2}$ partially relieved the inhibitory effect of EDTA, and the transformation frequency of the mutants was fourfold higher than that of the wild-type (Table 3).

These results suggest that DNA uptake is controlled by $\mathrm{Ca}^{2+}$ through the sensing properties of the $\mathrm{CiaR} / \mathrm{CiaH}$ system. Inactivation of the ciaR-ciaH operon reduces the requirement for $\mathrm{Ca}^{2+}$ without abolishing it. When the $\mathrm{Ca}^{2+}$ concentration is too low, the system is activated, $\mathrm{CiaH}$ is autophosphorylated, and phosphorylated CiaR blocks DNA entry. This correlates well with the observation that strains carrying the $\mathrm{ciaH}^{*}$ mutation are derepressed for this system and not naturally transformable, but can be electrotransformed (Seroude et al., 1993).

\section{Effect of $\mathrm{Ca}^{2+}$ on cefotaxime resistance}

The CiaR/CiaH system was discovered by isolating bacteria resistant to cefotaxime. The genetic and molecular analysis of these strains eventually showed that cefotaxime resistance results from a missense mutation in the ciaH sensor gene (Guenzi et al., 1994). We have seen that the sensor is most likely repressed by $\mathrm{Ca}^{2+}$ and becomes constitutively activated as a result of the missense $\mathrm{ciaH}^{*}$ mutation. Therefore $\mathrm{Ca}^{2+}$ might affect resistance to cefotaxime.
We cultivated several strains in MS medium without added $\mathrm{Ca}^{2+}$, supplemented with $50 \mathrm{mM}$ phosphate, or in the same defined medium containing $1 \mathrm{mM}$ phosphate and $5 \mathrm{mM} \mathrm{Ca}^{2+}$. The growth of all strains was similar in both media. When cefotaxime was added after $1 \mathrm{~h}$, at a concentration of $0.04 \mu \mathrm{g} \mathrm{ml}^{-1}$, the growth response was quite different with respect to the strains. The wild-type strain R800 grew in the medium at low $\mathrm{Ca}^{2+}$ and high phosphate concentrations in the presence of the antibiotic, but not in the medium at high $\mathrm{Ca}^{2+}$ concentration. Strain 800 ciaH $^{*}$ grew in both media, and strains inactivated in ciaH or ciaR could not grow in either medium. Resistance to cefotaxime in wild-type bacteria, therefore, is increased when $\mathrm{Ca}^{2+}$ is at a limiting concentration. This resistance is suppressed when $c i a R$ or ciaH are inactivated by an insertion. Constitutive activation of the operon by the $\mathrm{ciaH}^{*}$ mutation results in resistance independently of the addition of $\mathrm{Ca}^{2+}$ as an effector. Therefore it seemed judicious to search for proteins homologous to the $\mathrm{CiaH}$ protein, focusing the investigation on $\mathrm{Ca}^{2+}$ sensors.

\section{Search for homologies to CiaH protein}

Several proteins share homologies with $\mathrm{CiaH}$. They belong to the histidine kinase two-component system family (Stock et al., 1990), but their functions remain generally unknown. Homology is located in the cytoplasmic portion of the $\mathrm{CiaH}$ protein. In the extracytoplasmic region several fragments are conserved between $\mathrm{CiaH}$ and PhoQ from Salmonella typhimurium and E. coli (Fig. 6). These proteins are able to detect changes in $\mathrm{Ca}^{2+}$ concentration in the medium and are also protein kinases of the two-component system PhoP/PhoQ (Garcia-Vescovi et al., 1997). The ciaR gene also shares homology with several regulatory genes belonging to the family of two-component systems, which supports the proposition that $\mathrm{CiaR} / \mathrm{CiaH}$ system is a member of this family and therefore likely to be able to sense $\mathrm{Ca}^{2+}$ in the medium.

These results confirm the model in which the $\mathrm{CiaH}$ sensor is activated by $\mathrm{Ca}^{2+}$ starvation, resulting in autophosphorylation and phosphorylation of the CiaR protein, which in turn increases resistance to cefotaxime and blocks DNA uptake. Such a pleiotropic effect led us 


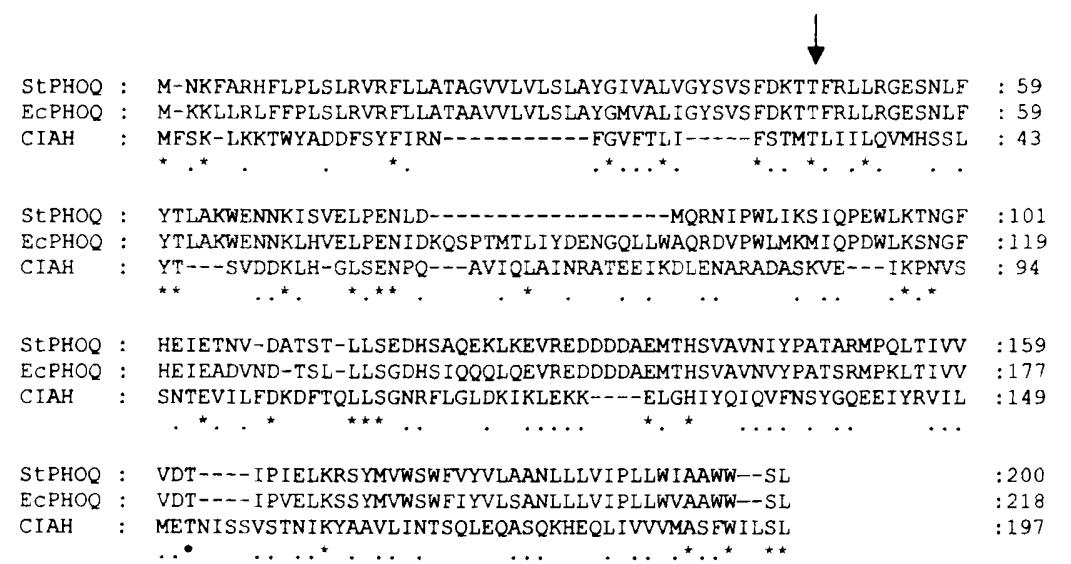

Fig. 6. Sequence comparisons of the $\mathrm{N}$ terminal parts of the $\mathrm{CiaH}$ and PhoQ proteins. The alignment was done using CLUSTAL. Asterisks indicate identical amino acids; dots indicate similar amino acids. The threonine residue involved in $\mathrm{Ca}^{2+}$ binding to PhoQ proteins is arrowed. StPHOQ, PhoQ protein of Salmonella typhimurium; ECPHOQ, PhoQ protein of E. coli; $\mathrm{CIAH}, \mathrm{CiaH}$ protein of Streptococcus pneumoniae.

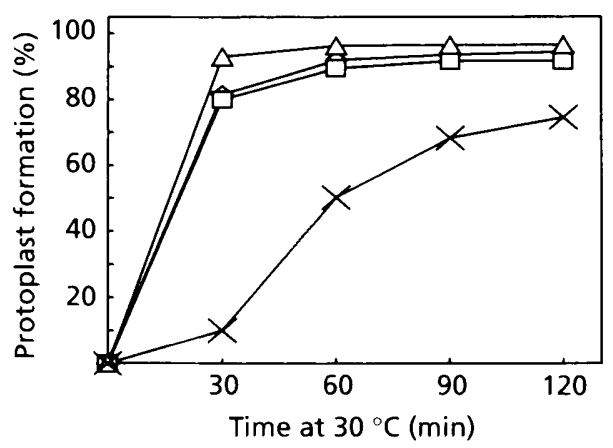

Fig. 7. Protoplast formation. The degree of protoplast formation was estimated by the sensitivity of samples to osmotic shock in water. $\square, 800 \mathrm{ciaR}^{\text {null }} ; \triangle, 800 \mathrm{ciaH}^{\text {null }} ; \times$, $800 \mathrm{CiaH}^{*} ; \diamond, \mathbf{R} 800$.

to suspect that other properties might be controlled by this system.

\section{Pleiotropic effects of mutations}

Growth of all strains in several complete media was very similar. We decided to compare the behaviour of the wild-type and mutated strains in their ability to form protoplasts for the following reasons: (1) antibiotic resistance and DNA uptake might involve alterations in cell-wall properties; and (2) competence activates protoplast formation (Seto \& Tomasz, 1975). Moreover, non-competent clones form protoplasts with more difficulty (Lacks \& Neuberger, 1975).

The strain $800 \mathrm{ciaH}^{*}$ formed protoplasts less easily than the wild-type strain (Fig. 7). The $800 \mathrm{ciaR}^{\text {null }}$ and $800 \mathrm{ciaH}^{\text {null }}$ strains behaved as the wild-type. The relationship between the ability to become competent and the ability to form protoplasts is strenghtened by these observations. As it was previously suggested that the gene $l y t A$, encoding a major autolysin (Garcia et al., 1985 ), is involved in forming protoplasts (Lacks \& Neuberger, 1975), we wondered whether lyt A could be inhibited by the $\mathrm{ciaH}^{*}$ mutation. A specific phenotype of lyt $A$ strains is their inability to lyse during the stationary phase or because of a penicillin treatment (Tomasz et al., 1970, 1988; Sanchez-Puelles et al., 1986). We have observed that all strains lyse spontaneously at the end of stationary phase or after penicillin treatment (data not shown). Thus the $c^{2} a H^{*}$ mutant does not behave as a lyt $A$ strain. This does not argue for a repression of the lyt $A$ gene by the $\mathrm{CiaR} / \mathrm{CiaH}$ system.

We also tested the sensitivity to lysis induced by deoxycholate. All strains lysed, although $800 \mathrm{ciaH}^{*}$ was more resistant. At a concentration of $0.01 \%$ deoxycholate, $80 \%$ of a 800 ciaH* culture had not lysed, whereas for the other strains only $30 \%$ of the culture had not lysed. The resistance of strain $800 \mathrm{ciaH}^{*}$ to deoxycholate and to a treatment inducing protoplast formation is interesting and might suggest that derepression of the ciaR-ciaH operon somehow affects cell wall biosynthesis. As choline is a major component of the cell wall and required for growth by $S$. pneumoniae (Badger, 1944; Tomasz, 1967), we studied the choline requirement of these mutants in MS medium without choline. Wild-type, $800 \mathrm{ciaH}^{\mathrm{null}}$ and $800 \mathrm{ciaH}^{*}$ strains could not grow in this medium, whereas 800 ciaR $^{\text {null }}$ grew normally without choline, suggesting regulation of cell wall synthesis by CiaR (data not shown).

\section{Effect of the $\mathrm{ciaH}^{*}$ mutation on susceptibility to antibiotics and toxins}

We compared the resistance of the wild-type strain $\mathrm{R} 800$ with the resistance of the isogenic strains $800 \mathrm{ciaR}^{\text {null }}$ and $800 \mathrm{ciaH}^{\text {null }}$ to antibiotics and toxic compounds belonging to several families (arsenate, arsenite, antimonite, erythromycin, norfoflaxin, novobiocin, penicillin and vancomycin). No differences were observed for arsenite, antimonite, erythromycin and vancomycin. On the other hand the penicillin resistance of $800 \mathrm{ciaH}^{*}$ was increased twofold. This is not surprising, since cefotaxime and penicillin are both $\beta$-lactams, often affecting the same target, which explains the frequent 
cross-resistance. The mutant was 1.5-2-fold more resistant to arsenate and novobiocin than the wild-type, whereas it was 2 -fold more sensitive to norfoflaxime.

\section{DISCUSSION}

We have investigated the function of the ciaR-ciaH locus. As already demonstrated by Guenzi et al. (1994), ciaH encodes a putative sensor protein that belongs to the family of signal-transducing histidine kinases. The adjacent gene, ciaR, encodes a protein related to the family of DNA-binding proteins involved in regulation of genes in response to environmental signals sensed by the histidine kinase.

Northern hybridizations using a ciaR-ciaH probe were performed on total RNA extracts from the pneumococcal strains $\mathrm{R} 800$ or 800 ciaH $^{*}$. A unique $2 \cdot 2 \mathrm{~kb}$ band was detected, confirming the hypothesis that the two genes constitute an operon. The size of this band was as expected from the DNA sequences of these two genes. Northern hybridizations on cultures containing different concentrations of phosphate indicated that phosphate affects the expression of this operon. In strain $\mathrm{R} 800$ optimal expression requires $50 \mathrm{mM}$ phosphate. In strain 800 ciaH $^{*}$, the transcripts were detected at high level, independent of the phosphate concentration. Therefore, the ciaR-ciaH operon is constitutively activated in this strain. These results are consistent with the observations of Guenzi et al. (1994), which indicated that the $\mathrm{ciaH}^{*}$ mutation does not abolish the function of the ciaH gene.

We isolated a mutation in ciaR that restores the competence lost in strain $801 \mathrm{C}$. This mutation is a $\mathrm{T}$ deletion in position 578-581, that induces a frameshift and a stop codon 15 bases downstream. Thus the CiaR protein in this mutant is truncated and contains only 125 residues instead of 224 . The protein has lost its $C$ terminal part, where the DNA-binding domain is localized. We can conclude that the expression of the ciaH $^{*}$ mutation requires a functional CiaR protein, which is what is expected for a constitutive activation of the system.

To study the function of the ciaR and ciaH genes, we constructed null mutants in a wild-type strain. The behaviour of these mutants is quite different: the ciaR null mutant is fully competent in phosphate-deprived medium and is able to grow in choline-free medium, whereas the ciaH null mutant is not competent in phosphate-deprived medium and requires choline for growth. These differences suggest that the CiaR protein is able to regulate some genes without phosphorylation by $\mathrm{CiaH}$ sensor protein. The difference of behaviour between ciaR null mutants and ciaH null mutants for competence in $\mathrm{CH}$-maleate medium argues against the hypothesis that $801 \mathrm{Crev}$ phenotype is due to a polar effect of ciaR mutation on ciaH.

A major contribution of this work is the identification of the nature of the environmental signal. We have found that, at a low concentration of $\mathrm{Ca}^{2+}, \mathrm{CiaH}$ is auto-

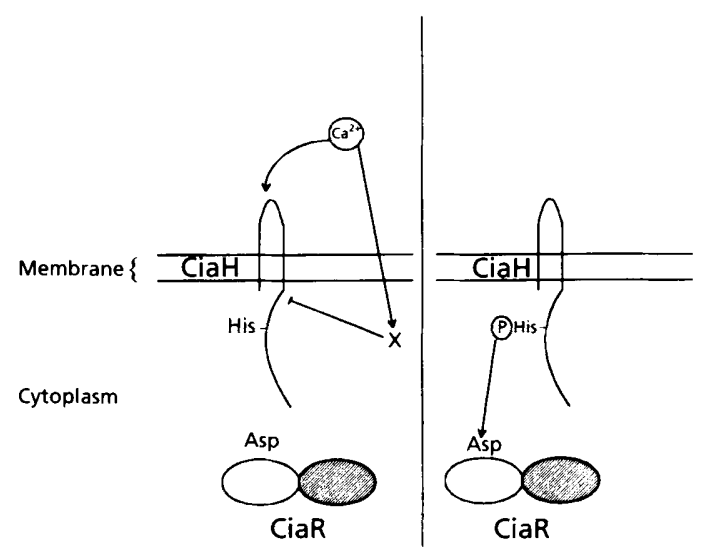

Fig. 8. $\mathrm{Ca}^{2+}$ sensing by the $\mathrm{CiaR} / \mathrm{CiaH}$ system. (a) In the presence of $\mathrm{Ca}^{2+}, \mathrm{CiaH}$ is unable to phosphorylate itself and to phosphorylate the CiaR protein. This inhibition results from a direct binding of $\mathrm{Ca}^{2+}$ to $\mathrm{CiaH}$ or indirectly by another mechanism not yet determined. (b) In $\mathrm{Ca}^{2+}$-deprived medium, $\mathrm{CiaH}$ autophosphorylates and phosphorylates the CiaR regulatory protein. This protein can regulate genes involved in competence and antibiotic resistance. His, phosphorylation site of $\mathrm{CiaH}$; Asp, phosphorylation site of CiaR. In the representation of the CiaR protein, the shaded part denotes the C-terminal region containing the DNA-binding domain; the white part denotes the $\mathrm{N}$-terminal region containing the phosphorylation site (Asp).

phospholylated, and thus phosphorylates CiaR, which in turn represses genes required for DNA uptake (Fig. 8). Simultaneously, genes conferring resistance to cefotaxime are activated. The addition of phosphate will reduce the available concentration of $\mathrm{Ca}^{2+}$ in the medium by its reaction with this ion. Therefore the activation of the operon by the addition of phosphate would be mediated by $\mathrm{Ca}^{2+}$ deprivation. This proposal is also supported by the presence of amino acids conserved between the extracytoplasmic parts of PhoQ and $\mathrm{CiaH}$ proteins. These results are consistent with the reports by Fox \& Hotchkiss (1957), Seto \& Tomasz (1976) and Trombe et al. (1992) showing that $\mathrm{Ca}^{2+}$ is required for transformation in pneumococcus. In this work we have described a regulatory system mediated by this ion. The control of competence via the CiaR/ $\mathrm{CiaH}$ system might be modulated by other genes, since when the ciaR-ciaH operon is inactivated, a low concentration of $\mathrm{Ca}^{2+}$ is required to transform $S$. pneumoniae.

The pleiotropic effect of the ciaH missense mutation that increases resistance to cefotaxime and blocks competence has been extended to other properties such as resistance to protoplast formation, to lysis induced by deoxycholate and to several antibiotics. Although it is difficult to account for the diversity of effects of the $\mathrm{ciaH}^{*}$ mutation, one possibility is a modification of the cell wall resulting from the derepression of this system.

An interesting phenotype of strain 800 ciaR $^{\text {null }}$ is the ability to grow without choline whereas the wild-type $S$. pneumoniae has an absolute requirement for this 
vitamin (Badger, 1944). The role of choline in the pneumococcal cell wall is poorly understood. This vitamin, incorporated in teichoic and lipoteichoic acids (Tomasz, 1967; Mosser \& Tomasz, 1970), is able to bind several proteins such as the pneumococcal surface protein (PspA) (Yother \& White, 1994) and activates the major amidase that autolyses pneumococcal cells in the stationary phase (Briese \& Hakenbeck, 1985; Sansz et al., 1988). It has been observed that when a wild-type culture is deprived of choline, the synthesis of peptidoglycan is inhibited. Mutations that eliminate the nutritional requirement for choline may affect the regulation of the teichoic acid transferase so that the transfer of choline-free teichoic acid to the peptidoglycan polymer may permit cell viability (Yother et al., 1998). The ciaR-ciaH operon may participate in this regulation of the cell wall biosynthesis. As a consequence, pleiotropic properties in ciaR ${ }^{\text {null }}$ mutant, such as choline independence for growth and competence extended to $\mathrm{CH}$ maleate medium, could be related to the cell wall. Thus, there are at least three regulations mediated via the cia operon: competence induction, resistance to cefotaxime, and cell wall biosynthesis.

\section{ACKNOWLEDGEMENTS}

The authors thank Dr J. P. Claverys for the gift of pR350 vector, Dr R. Hakenbeck for the gift of plasmid pEG2, and Dr A. J. Carpousis and Dr C. Kass for critical reading of the manuscript. This work was partially supported by an Institute Beecham-Inserm grant.

\section{REFERENCES}

Badger, E. (1944). The structural specificity of choline for the growth of type III pneumococcus. J Biol Chem 153, 183-191.

Briese, T. \& Hakenbeck, R. (1985). Interaction of the pneumococcal amidase with lipoteichoic acid and choline. Eur J Biochem 146, $417-427$.

Dintilhac, A. \& Claverys, J. P. (1997). The adc locus, which affects competence for genetic transformation in Streptococcus pneumoniae, encodes an $\mathrm{ABC}$ transporter with a putative lipoprotein homologous to a family of streptococcal adhesins. Res Microbiol 148, 119-131.

Dintilhac, A., Alloing, G., Granadel, C. \& Claverys, J. P. (1997). Competence and virulence of Streptococcus pneumoniae: adc and psaA mutants exhibit a requirement for $\mathrm{Zn}$ and $\mathrm{Mn}$ resulting from inactivation of putative $\mathrm{ABC}$ metal permease. Mol Microbiol 25, 727-739.

Dowson, C. G., Coffey, T. J., Kell, C. \& Whiley, R. A. (1993). Evolution of penicillin resistance in Streptococcus pneumoniae; the role of Streptococis mitis in the formation of a low affinity PBP2B in S. pneumoniae. Mol Microbiol 9, 635-643.

Fox, M. S. \& Hotchkiss, R. D. (1957). Initiation of bacterial transformation. Nature $179,1322-1325$.

Garcia, E., Garcia, J. L., Ronda, C., Garcia, P. \& Lopez, R. (1985). Cloning and expression of the pneumococcal autolysin gene in Escherichia coli. Mol Gen Genet 201, 225-230.

Garcia-Vescovi, E., Ayala, Y. M., Di Cera, E. \& Groisman, E. A. (1997). Characterization of the bacterial sensor protein PhoQ.J Biol Chem 272, 1440-1443.

Gasc, A. M., Giammarinaro, P., Richter, S. \& Sicard, M. (1998).
Organization around the $d n a A$ gene of Streptococcus pneumoniae. Microbiology 144, 433-439.

Guenzi, E., Gasc, A. M., Sicard, A. M. \& Hakenbeck, R. (1994). A two-component signal-transducing system is involved in competence and penicillin susceptibility in laboratory mutants of Streptococcus pneumoniae. Mol Microbiol 12, 505-515.

Hakenbeck, R., Tarpay, M. \& Tomasz, A. (1980). Multiple changes of penicillin-binding proteins in penicillin-resistant clinical isolates of Streptococcus pneumoniae. Antimicrob Agents Chemother 17, 364-371.

Hakenbeck, R., Tornette, S. \& Adkinson, N. F. (1987). Interactions of non-lytic $\beta$-lactam with penicillin-binding proteins in Streptococcus pneumoniae. J Gen Microbiol 157, 101-106.

Lacks, S. \& Neuberger, M. (1975). Membrane location of a deoxyribonuclease implicated in the genetic transformation of Diplococcus pneumoniae. J Bacteriol 124, 1321-1329.

Laible, G. \& Hakenbeck, R. (1987). Penicillin-binding proteins in $\beta$ lactam resistant laboratory mutants of Streptococcus pneumoniae. Mol Microbiol 1, 355-363.

Laible, G. \& Hakenbeck, R. (1991). Five independent combinations of mutations can result in low affinity penicillin-binding protein 2X of Streptococcus pneumoniae. J Bacteriol 173, 6986-6990.

Lefevre, J. C., Claverys, J. P. \& Sicard, M. A. (1979). Donor deoxyribonucleic acid length and marker effect in pneumococcal transformation. J Bacteriol 138, 80-86.

Makino, K., Shinagawa, H., Nakata, A. (1985). Regulation of the phosphate regulon of Escherichia coli K12: regulation and role of the regulatory gene phoR. J Mol Biol 185, 231-240.

Mejean, V., Claverys, J. P., Vasseghi, H. \& Sicard, A. M. (1981). Rapid cloning of specific DNA fragments of Streptococcus pneumoniae, hy vector integration into the chromosome followed by endonucleolytic excision. Gene 15, 289-293.

Mortier-Barriere, I., de Saizieu, A., Claverys, J.-P. \& Martin, B. (1998). Competence-specific induction of $\mathrm{rec} A$ is required for full recombination proficiency during transformation in Streptococcus pneumoniae. Mol Microbiol 27, 159-170.

Mosser, J. L. \& Tomasz, A. (1970). Choline-containing teichoic acid as a structural component of pneumococcal cell wall and its role in sensitivity to lysis by an autolytic enzyme. J Biol Chem $\mathbf{2 4 5}$, 287-298.

Sanchez-Puelles, J. M., Ronda, C., Garcia, J. L., Garcia, P., Lopez, R. \& Garcia, E. (1986). Searching for autolysin functions. Characterization of a pneumococcal mutant deleted in the $l y t A$ gene. Eur J Biochem 158, 289-293.

Sansz, J. M., Lopez, R. \& Garcia, J. L. (1988). Structural requirements of choline for 'conversion' of pneumococcal amidase. A new single-step procedure for purification of this autolysin. FEBS Lett 232, 308-312.

Selakovitch-Chenu, L., Seroude, L. \& Sicard, M. (1993). The role of penicillin binding protein 3 (PBP 3) in cefotaxime resistance in Streptococcus pneumoniae. Mol Gen Genet 239, 77-80.

Selakovitch-Chenu, L., Giammarinaro, P. \& Sicard, M. (1997). Molecular characterization of a mutation affecting the amount of Streptococcus pneumoniae penicillin-binding protein 3. Microb Drug Res 3, 259-262.

Seroude, L., Hespert, S., Selakovitch-Chenu, L., Gasc, A.-M., Lefrançois, J. \& Sicard, A. M. (1993). Genetic studies of cefotaxime resistance in Streptococcus pneumoniae: relationship to transformation deficiency. Res Microbiol 144, 389-394.

Seto, H. \& Tomasz, A. (1975). Protoplast formation and leakage of intramembrane cell components: induction by the competence activator substance in pneumococci. J Bacteriol 121, 344-353. 
Seto, H. \& Tomasz, A. (1976). Calcium-requiring step in the uptake of deoxyribonucleic acid molecules through the surface of competent pneumococci. J Bacteriol 126, 1113-1118.

Sicard, A. M. (1964). A new synthetic medium for Diplococcus pneumoniae and its use for the study of reciprocal transformation at the AmiA locus. Genetics 50, 31-44.

Stock, J. B., Stock, A. M. \& Mottonen, J. M. (1990). Signal transduction in bacteria. Nature 344, 395-400.

Thomas, R. (1955). Recherche sur la cinétique des transformations bactériennes. Biochim Biophys Acta 18, 467-481.

Tiraby, J. G. \& Fox, M. S. (1973). Marker discrimination in transformation and mutation of pneumococcus. Proc Natl Acad Sci USA 70, 3541-3545.

Tiraby, J. G. \& Fox, M. S. (1974). Marker discrimination and mutagenesis induced alterations in pneumococcal transformation. Genetics 77, 449-458.

Tiraby, J. G. \& Sicard, M. (1973). Integration efficiencies in DNAinduced transformation of pneumococcus. II. Genetic studies of mutants integrating all the markers with a high efficiency. Genetics 75, 35-48.

Tomasz, A. (1967). Choline in the cell wall of bacterium: novel type of polymer-linked choline in pneumococcus. Science 157, 694-697.

Tomasz, A. \& Hotchkiss, R. D. (1964). Regulation of the trans- formability of pneumococcal cultures by macromolecular cell products. Proc Natl Acad Sci USA 51, 480-487.

Tomasz, A., Albino, A. \& Zanati, E. (1970). Multiple antibiotic resistance in a bacterium with suppressed autolytic system. Nature 227, 138-140.

Tomasz, A., Moreillon, P. \& Pozzi, G. (1988). Insertional inactivation of the major autolysin gene of Streptococcus pneumoniae. J Bacteriol 170, 5931-5934.

Trombe, M. C., Clave, C. \& Manias, J. M. (1992). Calcium regulation of growth and differentiation in Streptococcus pneumoniae. J Gen Microbiol 139, 433-439.

Williamson, R., Hakenbeck, R. \& Tomasz, A. (1980). In vivo interaction of $\beta$-lactam antibiotics with the penicillin-binding proteins of Streptococcus pneumoniae. Antimicrob Agents Chemother 18, 629-637.

Yother, J. \& White, J. M. (1994). Novel surface attachment mechanism of the Streptococcus pneumoniae protein PspA. J Bacteriol 176, 2976-2985.

Yother, J., Leopold, K., White, J. \& Fischer, W. (1998). Generation and properties of a Streptococcus pneumoniae mutant which does not require choline or analogs for growth. J Bacteriol 180, 2093-2101.

Received 27 January 1999; revised 16 April 1999; accepted 20 April 1999. 